\title{
Analysis of genetic diversity among wild bermudagrass germplasm from southwest China using SSR markers
}

\author{
Y. Ling', X.-Q. Zhang' ${ }^{2}$ X. $\mathrm{Ma}^{2}$, S.-Y. Chen ${ }^{2}$, T.-T. Chen² and W. Liu ${ }^{2}$ \\ ${ }^{1}$ College of Veterinary Medicine, Sichuan Agricultural University, \\ Ya'an, Sichuan, P.R. China \\ ${ }^{2}$ Department of Grassland Science, Animal Science and Technology College, \\ Sichuan Agricultural University, Ya'an, Sichuan, P.R. China \\ Corresponding author: X.-Q. Zhang \\ E-mail: zhangxq8@hotmail.com
}

Genet. Mol. Res. 11 (4): 4598-4608 (2012)

Received March 23, 2012

Accepted June 29, 2012

Published October 17, 2012

DOI http://dx.doi.org/10.4238/2012.October.17.5

\begin{abstract}
Fifty-five wild accessions of bermudagrass (Cynodon dactylon) were collected from southwest China (Sichuan, Chongqing, Yunnan, Guizhou, and Tibet), and their genetic diversity was analyzed using simple sequence repeat markers. A total of 267 polymorphic bands were detected with 18 primer combinations. The genetic similarity among the accessions ranged from 0.688 to 0.894 with an average of 0.797 . All 55 wild accessions were clustered into 7 ecogeographic groups. Our data showed that the dendrogram was almost in accordance with geographic distribution, and accessions from the same collection sites tended to be clustered into the same group. A genetic differentiation analysis revealed that the percentage of genetic variance was 70.07 and $29.93 \%$ within and among groups, respectively. Finally, we discuss the implications of these results for C. dactylon in southwest China.
\end{abstract}

Key words: Cynodon dactylon; SSR; Genetic diversity; Cluster analysis 


\section{INTRODUCTION}

Cynodon dactylon, a perennial herbaceous plant of the grass subfamily Eragrostoideae, tribe Chlorideae, is a well-known turfgrass that grows in tropic, subtropic, and temperate zones (Harlan and De Wet, 1968; Taliaferro, 1995). It originates from Africa and is wildly distributed in South America, Africa, Europe, and South Asia (Dong and Shen, 2003). In China, C. dactylon is mostly distributed along and to the south of the Yellow River Valley (Tan, 1993).

Under natural growth conditions, $C$. dactylon has a seed-setting rate of 2.8-43.2, whereas the rate for self-pollination is only 0.01-8.09 (Richardson et al., 1978), suggesting higher genetic variation in natural populations. Over the past decades, several studies have examined morphology, physiology, and biochemistry in order to assess the diversity of C. dactylon (Liu et al., 2007). Modern techniques using DNA makers have been extensively used in studies of the genetic diversity of $C$. dactylon. Roodt et al. (2002) used the random amplified polymorphic DNA (RAPD) technique to determine the genetic relationship among $C$. dactylon cultivars in the South Africa. Caetano-Anollés et al. (1997) and Caetano-Anollés (1998) used DNA fingerprinting techniques to investigate the genetic relationships among $C$. dactylon and the DAF method to analyze the genomes of 2 varieties of Tifgreen and Tifdrawf. Mehmet et al. (2002) also used RAPD and DAF to study the hybrid intraspecific and interspecific genetic variation of $C$. dactylon. Using AFLP, Wu et al. (2004) reported the Nei's genetic similarity coefficients of the accessions to be 0.53-0.98 among C. dactylon in 11 different countries in Asia, Africa, Australia, and Oceania. They suggested that more representative samples from the areas of origin are needed to improve the accuracy of this estimate. Liu (2006) and Liu et al. (2007, 2008) analyzed the genetic diversity of the bermudagrass accessions in southwest China by RAPD, ISSRs, and RAMP. However, a large number of wild C. dactylon germplasms grow in southwest China; therefore, their genetic diversity deserves additional study at the DNA level.

Microsatellites or simple sequence repeats (SSRs) are repetitive sequences dispersed throughout the eukaryotic genome that have high mutation rates (Oliveira et al., 2006). This can produce high variability in the length of amplified DNA and high levels of heterozygosity (Ellegreen, 2004). These techniques have been successfully applied to the analysis of genetic diversity, relationships, and construction of genetic linkage maps in a wide range of species (e.g., Oysia japonica, Sorghum hybrid, Sudangrass, and Sorghum) (Guo et al., 2007; Zhan et al., 2008; Lu et al., 2009). However, few studies have used SSR to investigate the genetic diversity of wild $C$. dactylon.

To analyze and evaluate the genetic diversity of $C$. dactylon in southwest China, we collected 55 accessions of wild $C$. dactylon and studied their SSR polymorphisms. Our data may provide information for gathering, conserving, identifying, analyzing relationships, and breeding of C. dactylon.

\section{MATERIAL AND METHODS}

\section{Plant materials}

Fifty-five wild accessions of $C$. dactylon were sampled from southwestern China. A complete list of accession descriptions and putative geographical origins are provided in Table 1 and Figure 1. All genotypes were clone lines, which possess a unique genetic background. 
Table 1. Wild Cynodon dactylon L. Pers. accessions tested in this study.

\begin{tabular}{|c|c|c|c|c|}
\hline Order & Accession No. & Origin & Habit & Altitude (m) \\
\hline 1 & Sau9933 & Wenchuan, Sichuan & Roadside & 1210 \\
\hline 2 & Sau9935 & Maoxian, Sichuan & Wasteland & 1480 \\
\hline 3 & Sau9936 & Maoxian, Sichuan & Wasteland & 1460 \\
\hline 4 & Sau02011 & Wenchuan, Sichuan & Roadside & 1310 \\
\hline 5 & Sau02012 & Jinchuan, Sichuan & Roadside & 2150 \\
\hline 6 & Sau02015 & Jinchuan, Sichuan & Roadside & 1310 \\
\hline 7 & Sau02004 & Leibo, Sichuan & Flood land & 1200 \\
\hline 8 & Sau02005 & Huidong, Sichuan & Roadside & - \\
\hline 9 & Sau02006 & Ningnan, Sichuan & Roadside & - \\
\hline 10 & Sau0085 & Xichang, Sichuan & Flood land & 1380 \\
\hline 11 & Sau02053 & Xichang, Sichuan & Flood land & 1380 \\
\hline 12 & Sau0088 & Mianning, Sichuan & Field ridge & 1774 \\
\hline 13 & Sau02033 & Yuexi, Sichuan & Roadside & - \\
\hline 14 & Sau0099 & Panzhihua, Sichuan & Roadside & 1100 \\
\hline 15 & Sau0098 & Panzhihua, Sichuan & Woodland & 1120 \\
\hline 16 & Ly97017 & Panzhihua, Sichuan & Grassland & 1200 \\
\hline 17 & Sau02028 & Miyi, Sichuan & Hillside & 1620 \\
\hline 18 & Sau0095 & Yanbian, Sichuan & Field ridge & 1150 \\
\hline 19 & Sau9918 & Ya'an, Sichuan & Grassland & 600 \\
\hline 20 & Sau02055 & baoxing, Sichuan & Hillside & 1010 \\
\hline 21 & Sau02060 & Yingjing, Sichuan & Roadside & 720 \\
\hline 22 & Sau02061 & Tianquan, Sichuan & Riverside & 740 \\
\hline 23 & Sau02064 & Lushan, Sichuan & Hillside & 630 \\
\hline 24 & Sau02065 & Lushan, Sichuan & Riverside & 685 \\
\hline 25 & Sau9927 & Yibin, Sichuan & Flood land & 240 \\
\hline 26 & Sau9922 & Yibin, Sichuan & Riverside & 255 \\
\hline 27 & Sau9931 & Yibin, Sichuan & Flood land & 245 \\
\hline 28 & Sau9924 & Yibin, Sichuan & Roadside & 340 \\
\hline 29 & Sau9926 & Yibin, Sichuan & Wasteland & 260 \\
\hline 30 & Sau02041 & Yibin, Sichuan & Riverside & 250 \\
\hline 31 & Sau02042 & Yibin, Sichuan & Riverside & 250 \\
\hline 32 & Sau02045 & Liangping, Chongqing & Riverside & 400 \\
\hline 33 & Sau02046 & Liangping, Chongqing & Roadside & 380 \\
\hline 34 & Sau9942 & Changshou, Chongqing & Woodland & 305 \\
\hline 35 & Sau 9945 & Changshou, Chongqing & Flood land & 140 \\
\hline 36 & Sau9953 & Hechuan, Sichuan & Flood land & 130 \\
\hline 37 & Sau9947 & Jialing, Chongqing & Woodland & 230 \\
\hline 38 & Sau02050 & Wanzhou, Chongqing & Shipside & 150 \\
\hline 39 & Sau02048 & Wanzhou, Chongqing & Roadside & 490 \\
\hline 40 & Sau06001 & Yunyang, Chongqing & Flood land & 160 \\
\hline 41 & Sau02019 & Libo, Guizhou & Flood land & 370 \\
\hline 42 & Sau02020 & Libo, Guizhou & Flood land & 360 \\
\hline 43 & Sau02022 & Dushan, Guizhou & Roadside & 950 \\
\hline 44 & Sau02023 & Dushan, Guizhou & Field ridge & 970 \\
\hline 45 & Sau02024 & Dushan, Guizhou & Roadside & 810 \\
\hline 46 & Sau02025 & Dushan, Guizhou & Roadside & 890 \\
\hline 47 & Sau03001 & Bayi, Tibet & Garden & 3080 \\
\hline 48 & Sau03002 & Chayu, Tibet & Roadside & 2550 \\
\hline 49 & Sau03003 & Chayu, Tibet & Roadside & 2460 \\
\hline 50 & Sau03004 & Chayu, Tibet & Roadside & 2030 \\
\hline 51 & Sau03005 & Chayu, Tibet & Roadside & 1750 \\
\hline 52 & Sau02026 & Xiaoshao, Yunnan & Groove & 1900 \\
\hline 53 & Sau02027 & Xiaoshao, Yunnan & Roadside & 1910 \\
\hline 54 & Ly98010 & Kunming, Yunnan & Roadside & 1720 \\
\hline 55 & Sau02054 & Qiaojia, Yunnan & Roadside & 841 \\
\hline
\end{tabular}

\section{DNA extraction}

DNA was extracted using the cetyltrimethylammonium bromide (CTAB) method (Reichardt and Rogers, 1997). DNA concentration was estimated by the fluorescence intensities of ethidium bromide-stained samples on $0.8 \%$ agarose gels. 


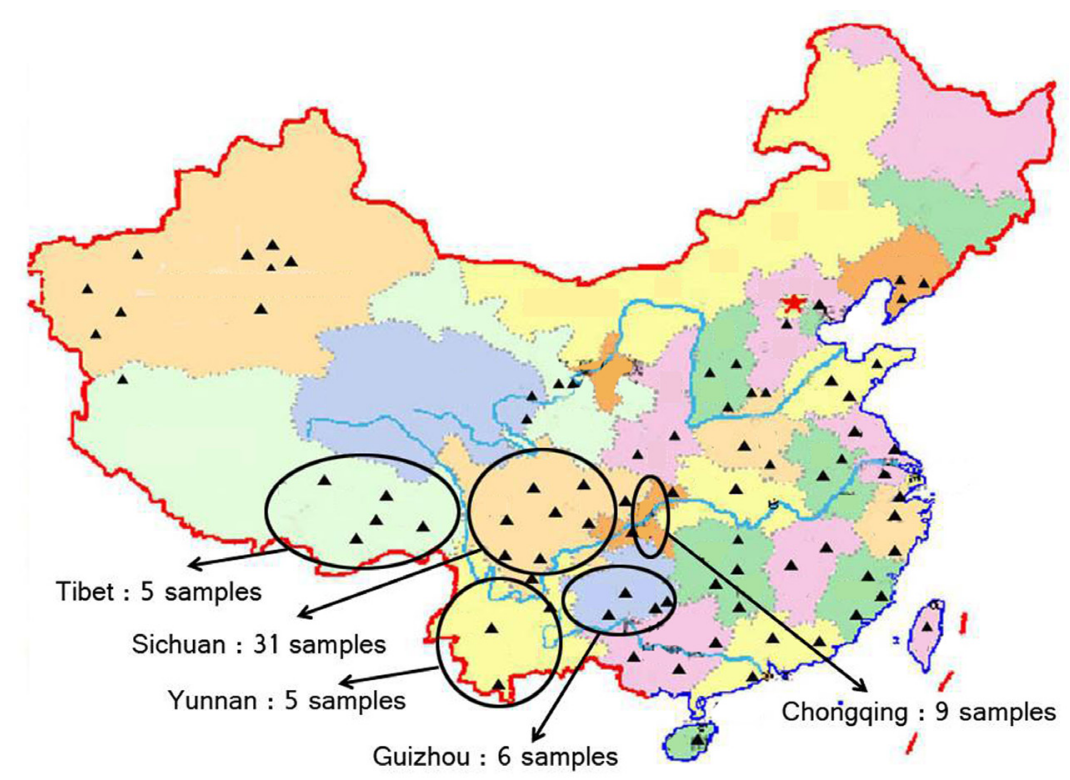

Figure 1. Chinese map showing the collection sites of the 55 samples of Cynodon dactylon L. Pers.

\section{Polymerase chain reaction (PCR) amplification}

A total of 18 primer pairs were used to assay the 55 bermudagrass accessions; these were EST-SSR primers from main cereal crops (Wang et al., 2005). Primer banding patterns that were difficult to score and those that failed to amplify consistently in all genotypes were excluded. Consequently, only 18 combinations were selected (Table 2). For SSR amplification, the total volume of the PCR was $15 \mu \mathrm{L}$ and contained $40 \mathrm{ng}$ template DNA, $1.5 \mathrm{mM}$ $\mathrm{Mg}^{2+}, 1 \mathrm{U}$ Taq DNA polymerase (Takara Biotechnology Co. Ltd., China), $240 \mathrm{nM} \mathrm{dNTP,} \mathrm{and}$ $0.4 \mu \mathrm{M}$ primer. PCR was performed using the following conditions: $94^{\circ} \mathrm{C}$ for $4 \mathrm{~min}$; 10 cycles at $94^{\circ} \mathrm{C}$ for $1 \mathrm{~min}, 53^{\circ} \mathrm{C}$ for $30 \mathrm{~s}$, and $72^{\circ} \mathrm{C}$ for $40 \mathrm{~s}$ with a $0.5^{\circ} \mathrm{C}$ decrease in annealing temperature per cycle; 35 cycles at $94^{\circ} \mathrm{C}$ for $1 \mathrm{~min}, 45^{\circ} \mathrm{C}$ for $30 \mathrm{~s}$, and $72^{\circ} \mathrm{C}$ for $40 \mathrm{~s}$; an extension at $72^{\circ} \mathrm{C}$ for $10 \mathrm{~min}$, and storage at $4^{\circ} \mathrm{C}$. The amplified fragments were separated on $6 \%$ denatured polyacrylamide gels (acrylamide:bisacrylamide, 19:1) in 1X TBE. After electrophoresis, the gel was stained with $\mathrm{AgNO}_{3}$ solution using a previously reported method (Xu et al., 2002) and photographed using the Gel Doc XR system (Bio-Rad Laboratories).

\section{Data analysis}

Unequivocally and consistently reproducible amplified SSR bands were scored as present (1) and absent (0). Smeared and weak bands were excluded. Fragments of the same molecular weight were considered to represent the same locus. To analyze the suitability of the SSR markers for evaluating genetic profiles of $C$. dactylon, the performance of the markers was measured using polymorphic information content (PIC). The PIC value for each locus was calculated as proposed by Roldán-Ruiz et al. (2000): 


$$
\mathrm{PIC}_{i}=2 f_{i}\left(1-f_{i}\right)
$$

where $P I C_{i}$ is the PIC of the locus $I ; f_{i}$ is the frequency of the amplified fragments (band present), and $1-f_{i}$ is the frequency of non-amplified fragments (band absent). The frequency was calculated as the ratio between the number of amplified bands at each locus and the total number of accessions. The PIC of each primer was calculated using the average PIC value from all bands of each primer pair.

The POPGENE software was also used to calculate the Shannon diversity index for SSR phenotypic data using the formula:

$$
H_{\mathrm{O}}=-\sum \pi \mathrm{i} \ln \pi \mathrm{i}
$$

where $\pi i$ is the frequency of a given SSR fragment. $H_{\mathrm{O}}$ was calculated at 2 levels: the average diversity within geographic groups $\left(\mathrm{H}_{\text {group }}\right)$ and the total diversity $\left(\mathrm{H}_{\mathrm{sp}}\right)$ (Wachira et al., 1995). The proportion of diversity among populations was estimated as $\left(\mathrm{H}_{\mathrm{sp}}-\mathrm{H}_{\text {group }}\right) / \mathrm{H}_{\mathrm{sp}}$ (Persson et al., 2001).

An unweighted pair-group method using arithmetic average (UPGMA) dendrogram was constructed based on the matrix of Nei's unbiased genetic distance (Nei and Li, 1979). Principal coordinates analyses were conducted to ordinate relationships among populations with Nei's distance matrix (NTSYS-pc version 2.11x; Rohlf, 2000). In order to test whether there was a correlation between genetic distances and geographical distances $(\mathrm{km})$ among populations, a Mantel test was performed using the NTSYS-pc program 2.11x with 3000 permutations.

\section{RESULTS AND DISCUSSION}

\section{SSR polymorphism}

Amplification from 55 C. dactylon DNA samples using the 18 primer pairs (Table 2) produced a total of 353 DNA bands, of which 267 were polymorphic (average of 19.61 bands per primer pair, Table 3). Polymorphic bands corresponding to $75.10 \%$ ranged from 50 to 1700 bp in size. To determine the PIC values of each primer pair, we analyzed the mean PIC values for all loci. As a result, we obtained high PIC values for the primers SG26 (0.4565) and SG22 (0.4339) and a low PIC value for the primer W17 (0.1668) (Table 3). The average PIC value for a primer pair was 0.3307 . A comparison of the frequency of polymorphic bands at each locus with the average PIC value of each locus showed that a greater number of polymorphic bands were associated with lower PIC values. While the results were similar to those obtained using RAPD markers (Liu, 2006), they identified a higher degree of genetic polymorphism than ISSRs and RAMP markers (Liu et al., 2007, 2008). This suggests that utilizing SSR marker is more feasible and effective. These results suggested that there is a rich genetic diversity among the wild $C$. dactylon based on SSR markers. SSR fingerprint patterns in $C$. dactylon L. Pers. amplified by primer SG26 numbers 1-55 are shown in Figure 2.

\section{Genetic similarity analysis}

Nei-Li genetic similarity coefficients were calculated using the NTSYS-pc2.10t soft- 
ware, and a dendrogram was constructed by UPGMA. Our data showed that there were significant differences in genetic diversity between the samples tested. Nei's genetic similarity coefficient of the accessions tested ranged from 0.688 to 0.894 . The average Nei's coefficient was 0.797 , and the transformer was 0.206 . The similarity coefficient matrix showed that $C$. dactylon collected from Leibo, Sichuan (Sau02004), and Huidong, Sichuan (Sau02005), had the lowest genetic similarity coefficient and the largest genetic distance, while $C$. dactylon collected from Chayu, Tibet (Sau03005), and Xiaoshao, Yunnan (Sau02027), had the highest degree of genetic similarity and the smallest genetic distance.

\section{Table 2. Primer sequences used in SSR analyses of Cynodon dactylon L. Pers.}

\begin{tabular}{|c|c|c|}
\hline Primers & Sequences $\left(5^{\prime}-3^{\prime}\right)$ & Sequences $\left(5^{\prime}-3^{\prime}\right)$ \\
\hline SG26 & TGGCGGACATCCTATT & GGAGAGCCCGTCACTT \\
\hline W6 & GTCCAGCTCTCGGATCTTGG & TGCATCCAAACAAGCCATGC \\
\hline M31 & GAAGTCGCTGATGAGAACGTAACC & GCTAGCTAGTGTGAGTTCTTCCGC \\
\hline S1 & TCACCAGACCACCAGCTTC & GAGAACGGGCCAAGGTACT \\
\hline M26 & CTGTCGTAAGAGCGCCAACAG & GTCTGAACGATGAACAGTACACGC \\
\hline SG3 & CCAACCGAGTCGCTGATG & GTGGACTCTGTCGGGGCACTG \\
\hline SG22 & TGGGCAGGGTATCTAACTGA & GCC TTTTTCTGAGCCTTGA \\
\hline M22 & GAGAGGTCGTCGTCGCTACTG & GAGACCAGATTCTTGGAACGGTAA \\
\hline SG20 & TGTATGGCCTAGCTTATCT & CAACAAGCCAACCTAAA \\
\hline SG25 & ССТССТТТТССТССТССТССС & TCAGAATCCTAGCCACCGTTG \\
\hline $\mathrm{R} 45$ & ATCGTTGCCTCGTAACAACC & ACCTGCAACTGCCAGAAGAG \\
\hline $\mathrm{R} 38$ & GTCATCTACCACACCCAGCC & CTTGGTCCAACCCGAACTTA \\
\hline S11 & GAGGGCGTACAGGAAGAACA & CCGAGAAGGACTTGGTGAAG \\
\hline SG29 & AATGAGGAAAATATGAAACAAGTACCAA & AATAACAAGCGCAACTATATGAACAATAAA \\
\hline W17 & GTGGCAGGCAGGCAAGCAAG & TGACGAGCTCATCGTCGTAG \\
\hline S5 & GTGGACGATGGATGGATCA & ATCACCACTGCCTCTCACAA \\
\hline $\mathrm{R} 2$ & AAGTCCGTCGACAGGATGAG & GCT GCTCTTCCTTGTGGCTA \\
\hline M48 & TGGACGATCTGCTTCTTCAGG & GAAGGCTTCTTCCTCGAGTAGGTC \\
\hline
\end{tabular}

Table 3. Amplification results from 18 primer combinations.

\begin{tabular}{|c|c|c|c|c|}
\hline Primer pairs & Total No. of polymorphic bands & No. of polymorphic bands & Polymorphic bands (\%) & PIC \\
\hline SG26 & 18.00 & 16.00 & 88.89 & 0.4565 \\
\hline W6 & 21.00 & 14.00 & 66.67 & 0.3512 \\
\hline M31 & 25.00 & 17.00 & 68.00 & 0.3464 \\
\hline S1 & 20.00 & 12.00 & 60.00 & 0.3284 \\
\hline M26 & 25.00 & 19.00 & 76.00 & 0.3832 \\
\hline SG3 & 17.00 & 14.00 & 82.35 & 0.3749 \\
\hline SG22 & 26.00 & 25.00 & 96.15 & 0.4339 \\
\hline M22 & 16.00 & 12.00 & 75.00 & 0.3797 \\
\hline SG20 & 16.00 & 13.00 & 81.25 & 0.2585 \\
\hline SG25 & 19.00 & 18.00 & 94.74 & 0.4120 \\
\hline R45 & 14.00 & 11.00 & 78.57 & 0.3016 \\
\hline R38 & 15.00 & 12.00 & 80.00 & 0.3012 \\
\hline S11 & 22.00 & 15.00 & 68.18 & 0.2347 \\
\hline SG29 & 22.00 & 21.00 & 95.45 & 0.3560 \\
\hline W17 & 14.00 & 7.00 & 50.00 & 0.1668 \\
\hline S5 & 19.00 & 8.00 & 42.11 & 0.3026 \\
\hline $\mathrm{R} 2$ & 19.00 & 10.00 & 52.63 & 0.2783 \\
\hline M48 & 24.00 & 23.00 & 95.83 & 0.2859 \\
\hline Total & 353.00 & 267.00 & & \\
\hline Average & 19.61 & 14.83 & 75.10 & 0.3307 \\
\hline
\end{tabular}

$\mathrm{PIC}=$ polymorphic information content. 


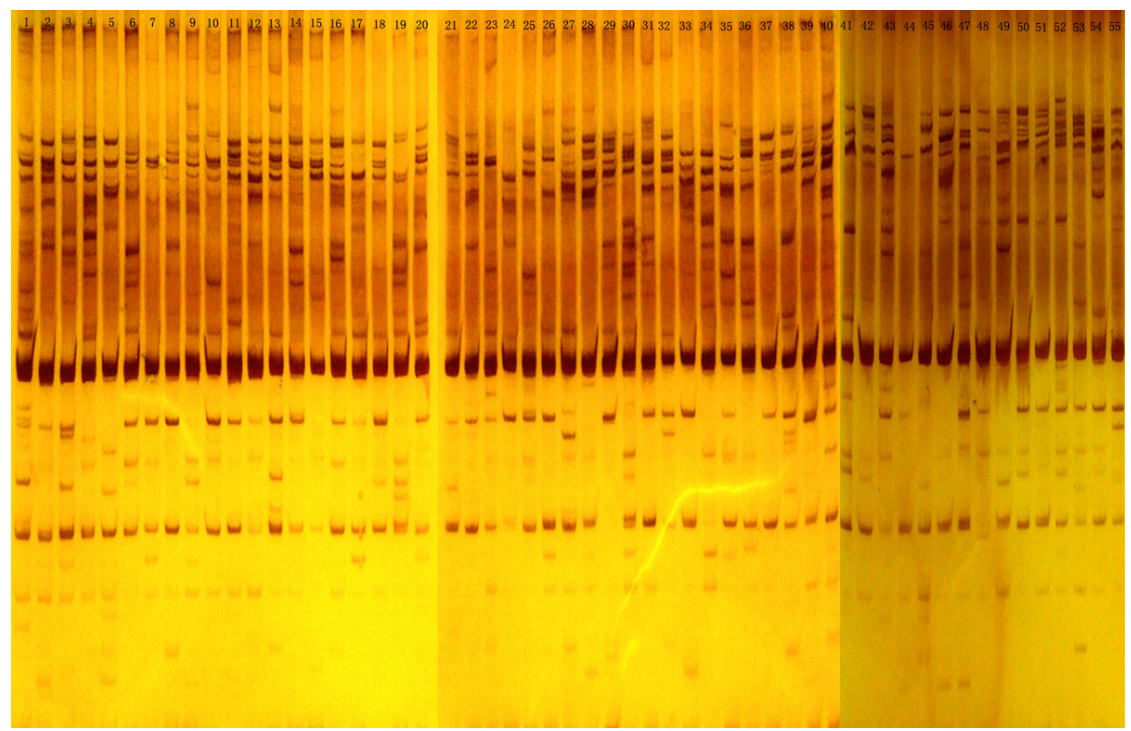

Figure 2. SSR fingerprint patterns in Cynodon dactylon L. Pers. amplified by primer SG26. Lanes 1 to 55 are the same as described in Table 1.

According to Zhao Ruzhi's division of the physico-geographical regionalization in southwest region (Zhao, 1997) and the different ecological and geographical environments of the sampling places, 55 C. dactylon materials were divided into 7 eco-geographical groups: Aba Sichuan, Yaan Sichuan, Panzhihua-Xichang Sichuan, Yibin Sichuan, Chongqing, Yunnan, and Guizhou, Tibet (Table 4). The genetic similarity (GS) and distance (GD = 1 - GS) of the 7 eco-geographical groups represent the level of genetic diversity within the group. We found an increase in GD between the samples within a group, which was correlated with increased genetic diversity. As shown in Table 4, the Yunnan and Guizhou groups had the highest average GD, Shannon index, and Simpson index (Nei's gene diversity).

Table 4. Genetic polymorphism indexes of 6 eco-geographical groups of Cynodon dactylon L. Pers.

\begin{tabular}{lccccccc}
\hline Groups & $\mathrm{GD}$ & $\mathrm{D}$ & $H_{\mathrm{O}}$ & $H_{\text {between }}$ & $H_{\text {group }}$ & $H_{\text {sp }}$ & $H_{\text {within }}$ \\
\hline A'ba, Sichuan & 0.1830 & 0.1872 & 0.2783 & 0.3805 & 0.2666 & 0.7007 & 0.2993 \\
Ya'an, Sichua & 0.1944 & 0.1935 & 0.2910 & & & & \\
Panxi region & 0.1862 & 0.1615 & 0.2423 & & & \\
Yibin, Sichua & 0.1835 & 0.1836 & 0.2736 & & & \\
Chongqing & 0.1855 & 0.1678 & 0.2522 & & & \\
Yunnan and Guizhou & 0.2199 & 0.2228 & 0.3286 & & & \\
Tibet & 0.2125 & 0.1330 & 0.2002 & & & \\
\hline
\end{tabular}

GD = genetic distance; $\mathrm{D}=$ Simpson index; $\mathrm{H}=$ Shannon index.

For the various eco-geographical groups, the species level of phenotypic diversity $\left(\mathrm{H}_{\mathrm{sp}}\right)$ was 0.2666 , while the population level of phenotypic diversity was $0.3805\left(\mathrm{H}_{\text {group }}\right)$. Phenotypic diversity within and among groups was $0.7007\left(\mathrm{H}_{\text {within }}\right)$ and $0.2993\left(\mathrm{H}_{\text {between }}\right)$, respectively. These results are consistent with those obtained by SRAP analysis (Yi et al., 2008). 


\section{Cluster analysis}

Based on the genetic similarity coefficient, 55 samples were tested by UPGMA cluster analysis (Figure 3). UPGMA cluster analysis indicated that when GS $=0.81,55$ wild accessions were clustered into 6 groups. This suggested that there was a strong correlation between the genetic relationships and growing locations. In general, samples from the same eco-geographical environment were clustered into a single group. Cluster I contained samples from Yunnan, which had similar climates. The samples from the Tibet region formed one group, cluster III, which was in the alpine cold meadow of the edge of the Tibetan plateau at a height of 1700-3000 $\mathrm{m}$ above sea level. Thus, this environment differed from other groups and was classified into its own branch. The sample from Yibin Sichuan (Sau992629) differed from the others. Sample 29 (Sau9926) also differed from the others. The leaf texture was smooth; the height of plant was slightly below average, and the branch density was high. This sample was clustered in a group by itself, forming Cluster II. These results are consistent with those of Yi et al. (2008). Samples from Panzhihua-Xichang Sichuan and some samples from Aba Sichuan formed cluster IV. Cluster V contained samples from Guizhou. However, this correlation was not applicable to other groups. Cluster VI contained various sample types and had a total of 32 samples, including those from Chongqing, Sichuan, Aba Yaan, Yibin, and others. Similar results were reported by Liu et al. (2007), who analyzed 42 accessions by ISSR. This might have resulted from the number of collected samples.

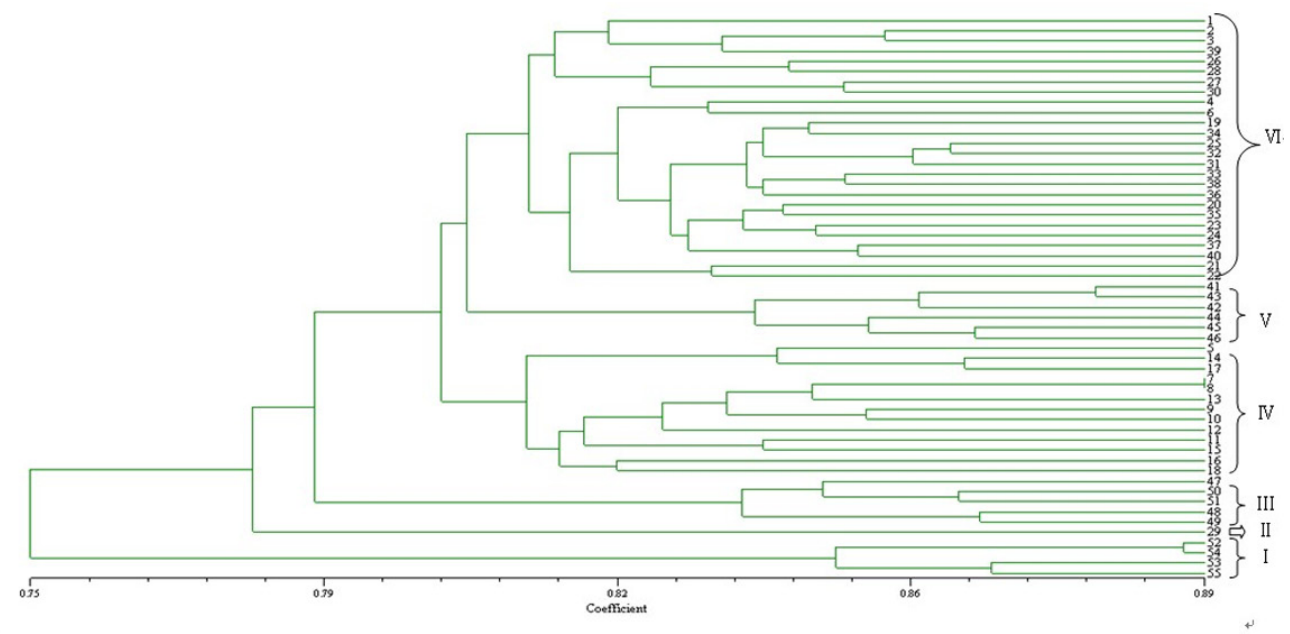

Figure 3. UPGMA dendrogram for Cynodon dactylon L. Pers. based on Nei-Li's genetic similarity coefficients.

\section{Cluster analysis of eco-geographical group}

To examine the relationships among all eco-geographical groups, NTSYS-PC was used for cluster analysis of UPGMA. The 8 tested eco-geographical groups were re-clustered into 7 main groups (Figure 4).

Groups from ABa, YaAn, and YiBin, belonging to Sichuan Province or Tibet Province, were still individually clustered. In contrast, the groups from Yunnan and Guizhou, which were 
both from the Yungui Plateau, were clustered into a single group. Further, samples from the same eco-geographical environment were generally clustered into a single group, which was consistent with the clustering results. However, this correlation was not applicable to other groups. The Aba and Yaan regions were grouped together. The Panzhihua-Xichang and Chongqing regions were grouped together. Panzhihua and Xichang regions are located in the central subtropic geographical and climate zone; they have a unique climate and environment, called the dry-and-hot valley. Due to a vertical zonal change, its high terrain and deep valley represents a special terrain in South China. This region has a south subtropical climate in the subtropical climate zone, while Chongqing belongs to the central subtropical humid climate. However, Panzhihua, Xichang region, and Chongqing region were grouped together. Similar results in $C$. dactylon were reported by Yi et al. (2008). A possible explanation for this result could be that the NTSYS-pc cluster analysis artificially divided the groups. The samples from Aba, Panzhihua, and Xichang belonging to Sichuan were clustered together, which similarly did not follow this rule. This was probably due to the mixed-mating breeding system and high levels of asexual reproduction in bermudagrass. Additionally, human activities and flood scouring may have increased reproduction in different places.

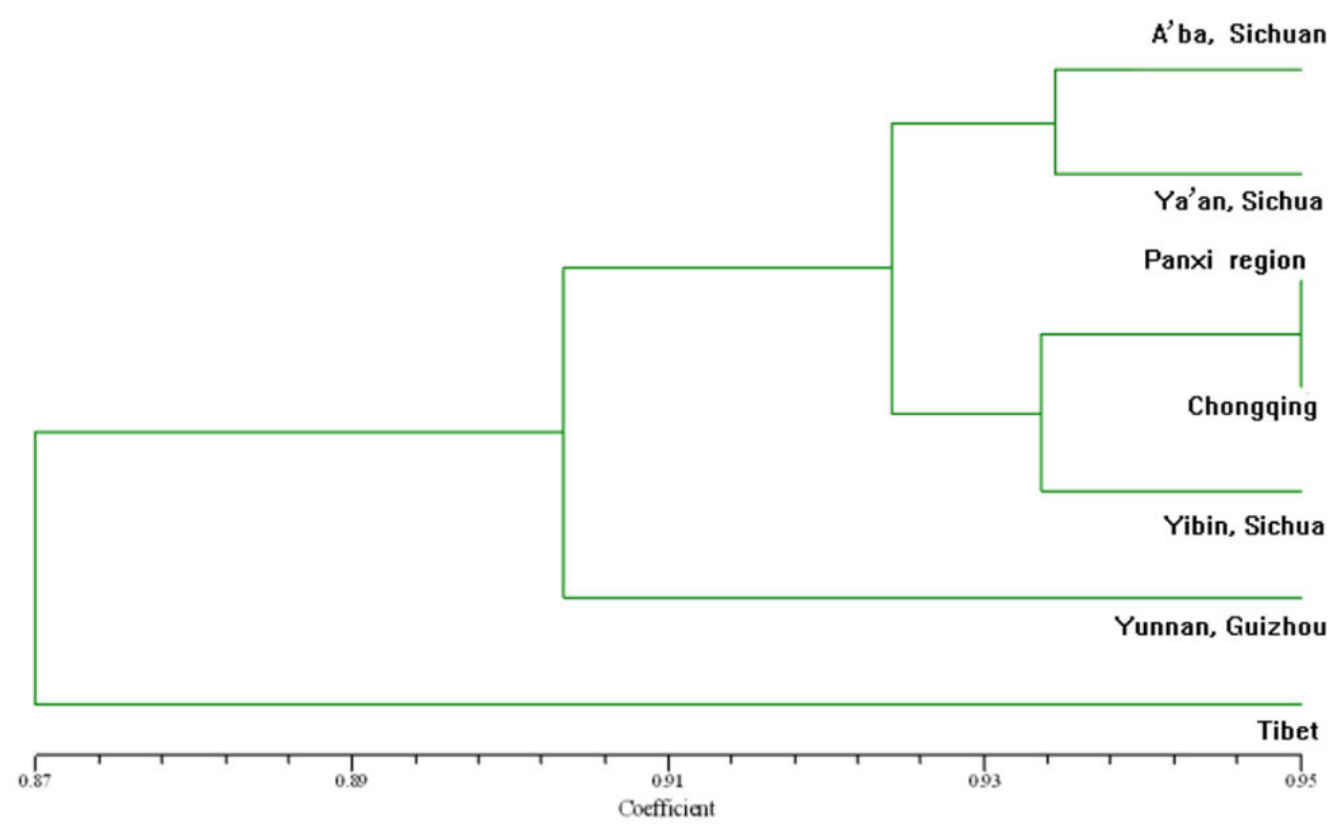

Figure 4. Dendrogram of 7 eco-geographical groups based on Nei's unbiased measures of genetic identity.

Our analysis of the genetic diversity using SSRs may contribute to protection plans and breeding of new varieties of $C$. dactylon. As described above, there are abundant wild $C$. dactylon in southwest China. However, because it has a high capability of agamogenesis and a rapid growth rate, the genetic diversity of $C$. dactylon has been reduced in recent years by human activity and flooding. We have shown that SSRs provide a rapid and effective tool for resolving the genetic polymorphisms in $C$. dactylon. Our study should help identify different lines and enable breeding of new cultivars of C. dactylon in the future. 


\section{ACKNOWLEDGMENTS}

Research supported by the National Science and Technology Supporting Project (\#2011BAD17B03), the Earmarked Fund for Modern Agro-Industry Technology Research System (\#CARS-35-05) and the Double-Support Plan of the Sichuan Agricultural University (\#2013). We are thankful to Dr. Bo Xie for his comments and help on the manuscript.

\section{REFERENCES}

Caetano-Anollés G (1998). Genetic instability of bermudagrass (Cynodon) cultivars 'Tifgreen' and 'Tifdrawf' detected by DAF and ASAP analysis of accession and off-types. Euphytica 101: 165-173.

Caetano-Anollés G, Callahan LM and Gresshoff PM (1997). The origin of bermudagrass (Cynodon) offTypes inferred by DNA amplification fingerprinting. Crop Sci. 37: 81-87.

Dong KH and Shen YX (2003). Forage Production Science. China Agricultural Press, Beijing.

Ellegren H (2004). Microsatellites: simple sequences with complex evolution. Nat. Rev. Genet. 5: 435-445.

Guo HL, Liu JX, Gao H, He Q, et al. (2007). Establishment of DNA fingerprint for eleven new strains of Zoysia japonica by SSR. Acta Pratacult. Sin. 16: 53-59.

Harlan JR and De Wet JMJ (1968). Sources of variation in Cynodon dactylon (L.) Pers. Crop Sci. 9: 774-778.

Liu W (2006). Genetic Diversity of Wild Cynodon dactylon Germplasm in Southwest of China and Lawny Value Study. Sichuan Agricultural University, Yaan.

Liu W, Zhang XQ, Li F, Ma X, et al. (2007). Genetic diversity of bermudagrass accessions in south-west China by ISSR molecular markers and geographic provenance. Acta Pratacult. Sin. 16: 55-61.

Liu W, Zhang XQ, Li F and Ma X (2008). Genetic Diversity of Cynodon dactylon accessions based on RAMP markers in hengduan mountains from southwest of China. Seed 27: 56-59.

Lu J, Lu YY, Li JQ, Zhan QW, et al. (2009). Simple sequence repeat (SSR) primer designing and construction of a genetic map of Sorghum bicolor x S. sudanense. Chin. J. Grassland 31: 28-33.

Mehmet K, Sukumar S, Allan Z, Johnie NJ, et al. (2002). Genetic diversity among forage bermudagrass (Cynodon spp.): evidence from chloroplast and nuclear DNA fingerprinting. Crop Sci. 42: 2118-2127.

Nei M and Li WH (1979). Mathematical model for studying genetic variation in terms of restriction endonucleases. Proc. Natl. Acad. Sci. U. S. A. 76: 5269-5273.

Oliveira ED, Pádua JG, Zucchi MI, Vencovsky R, et al. (2006). Origin, evolution and genome distribution of microsatellites. Genet. Mol. Biol. 29: 294-307.

Persson K, Diaz O and von Bothmer R (2001). Extent and patterns of RAPD variation in landraces and cultivars of rye (Secale cereale L.) from northern Europe. Hereditas 134: 237-243.

Reichardt M and Rogers S (1997). Preparation of Genomic DNA From Plant Tissue. In: Current Protocols in Molecular Biology (Ausubel FM, Brent R, Kingston RE and Moore DD, eds.). JohnWiley \& Sons, New York, 233-237.

Richardson WL, Taliaferro CM and Ahring RM (1978). Fertility of eight bermudagrass clones and open-pollinated progeny from them. Crop Sci. 18: 332-334.

Rohlf FJ (2000). NTSYSpc: Numerical Taxonomy and Multivariate Analysis System. Version 2.11x. Exeter Software, Setauket, New York.

Roldán-Ruiz I, Dendauw J, Van Bockstaele E, Depicker A, et al. (2000). AFLP markers reveal high polymorphic rates in ryegrasses (Lolium spp.). Mol. Breed. 6: 125-134.

Roodt R, Spies JJ and Burger TH (2002). Preliminary DNA fingerprinting of the turfgrass Cynodon dactylon (Poaceae: Chloridoideae). Bothalia 32: 117-122.

Taliaferro CM (1995). Diversity and vulnerability of bermuda turfgrass species. Crop Sci. 35: 327-332.

Tan JQ (1993). Chinese Ground Covers of Lawn. Science and Technology Literature Press, Beijing.

Wachira FN, Waugh R, Hackett CA and Powell W (1995). Detection of genetic diversity in tea (Camellia sinensis) using RAPD markers. Genome 38: 201-210.

Wang ML, Barkley NA, Yu JK, Dean RE, et al. (2005). Transfer of simple sequence repeat (SSR) markers from major cereal crops to minor grass species for germplasm characterization and evaluation. Plant Genet. Res. 3: 45-57.

Wu YQ, Taliaferro CM, Bai GH and Anderson MP (2004). AFLP analysis of Cynodon dactylon (L.) Pers. var. dactylon genetic variation. Genome 47: 689-696.

Xu SB, Tao YF, Yang ZQ and Chu JY (2002). A simple and rapid methods used for silver staining and gel preservation. Yi Chuan 24: 335-336. 
Yi YJ, Zhang XQ, Huang LK, Ling Y, et al. (2008). Genetic diversity of wild Cynodon dactylon germplasm detected by SRAP markers. Yi. Chuan 30: 94-100.

Zhan QW, Li JQ, Wang BH and Li YF (2008). Establishment of DNA fingerprinting for 42 sorghum and sudangrass accessions and 2 sorghum-sudangrass hybrids. Acta Pratacult. Sin. 17: 85-92.

Zhao RZ (1997). A study of the physico-geographical regionalization in southwest region. J. Southwest China Normal Univ. 22: 193-198. 